\title{
Erratum: Biotech entrepreneur, educate thyself!
}

\section{Emily Waltz}

Bioentrepreneur, published online 15 December 2005, corrected 27 March 2006; doi:10.1038/bioent896

In the online version of this article (paragraph 4), Chad Walton is incorrectly said to have graduated from a dual-degree program. The text should read, “...Chad Walton, who received a master of biomedical technology (MBT) from the University of Calgary....” The program with the eight students he is referring to is the MBT program, not the dual-degree program. The MBT program does, however, have a business component. The error has been corrected in the HTML version of the article.

\section{Erratum: European GMO labeling thresholds impractical and unscientific} Florian Weighardt

Nat. Biotechnol. 24, 23-25 (2006), corrected 27 March 2006

In the print version of this article and the version published online, several inaccuracies were introduced into the text through editorial modifications. On page 23, column 2, rows 3-4, the text: "It is now more than three years since the legislation was first introduced...." should have read "...more than five years...." On page 24, column 1, rows 35-37: "Currently, the method of choice for transgenic sequence detection is real-time PCR." should have read “...for transgenic sequence quantification...." Page 24, column 1, rows 51-55: "CRMs are prepared from certified seeds of the GM inbred line and of the non-GM parental variety used for the transformation are homogenized and grinded to powder." should have read, "For the GM inbred line and the non-GM parental variety used for the transformation, CRMs are prepared from certified seeds, homogenized and grinded to powder." On page 25, column 1, rows 22-25: "The EU legislators continue to fudge; the current regulation 1829/2003 (ref. 4) uses the same imprecise 1\% threshold as its predecessor $49 / 2000$ (ref. 2). And the EC's most recent recommendation $(2004 / 787 / 2000)^{17}$ only partly...." should have read “....uses the same imprecise threshold definition as its predecessor 49/2000, which introduced a 1\% threshold ${ }^{2}$. And the EC's most recent recommendation (2004/787/ EC) only partly..." The errors have been corrected in the PDF version of the article.

\section{Erratum: Biotech entrepreneur, educate thyself!}

Emily Waltz

Nat. Biotechnol. 24, 131-132 (2006), corrected 27 March 2006

In the print version of this article (paragraph 4 and picture caption), Chad Walton is incorrectly said to have graduated from a dual-degree program. The text should read, “...Chad Walton, who received a master of biomedical technology (MBT) from the University of Calgary....” The caption should read, "Entrepreneur and MBT graduate Chad Walton: just do it." The program with the eight students he is referring to is the MBT program, not the dual-degree program. The MBT program does, however, have a business component. The error has been corrected in the PDF version of the article.

\section{Erratum: Biogenerics at the crossroads}

\section{Carole S Ben-Maimon \& Rob Garnick}

Nat. Biotechnol. 24, 268 (2006), corrected 27 March 2006

In the print version of this article and the version originally published online, Carole Ben-Maimon was incorrectly listed as president and CEO of Barr Pharmaceuticals. She is, in fact, president and COO of Duramed Research, a subsidiary of Barr Pharmaceuticals. Her email address was also incorrect; her correct email address is cbenmaimon@barrlabs.com. The error has been corrected in the PDF version of the article. 